\title{
KEMAMPUAN MENULIS PUISI BEBAS DENGAN TEMA NILAI-NILAI KARAKTER BANGSA MAHASISWA SEMESTER GENAP 2017-2018 STKIP BUDIDAYA BINJAI
}

\author{
Fheti Wulandari Lubis \\ STKIP Budidaya Binjai \\ wulanlubis119@gmail.com
}

\begin{abstract}
ABSTRAK
Penelitian ini bertujuan untuk mengetahui kemampuan mahasiswa semester genap 20172018 STKIP Budidaya Binjai dalam menulis puisi bebas dengan tema nilai-nilai karakter bangsa. Metode yang digunakan dalam penelitian ini adalah metode penelian kualitatif. Alasan penulis menggunakan metode tersebut karena penulis berupaya mengetahui kemampuan mahasiswa dalam materi menulis puisi serta pemahaman mahasiswa tentang nilai-nilai karakter banga. Populasi penelitian berjumlah 51 orang. Instrument penelitian ini ialah dengan menggunakan teknik dokumentasi dan pengamatan secara langsung. Hasil penelitian membuktikan bahwasannya tema dalam menulis sebuh puisi bisa dengan menggunakan nilai-nilai karakter bangsa. Hal ini dapat dilihat dari nilai rata-rata mahasiswa semester genap 2017-2018 dengan nilai persentase 75. Selain itu tanpa disadari mahasiswa semester genap 2017-2018 STKIP Budidaya Binjai sadar akan nilainilai karakter bangsa tersebut dan diaplikasikannya dalam kehidupan sehari-harinya.
\end{abstract}

kata kunci : puisi bebas, nilai-nilai karakter bangsa

\section{PENDAHULUAN}

\section{Latar Belakang Masalah}

Salah satu bentuk karya sastra adalah puisi. Puisi adalah kata-kata yang disusun dalam bentuk tertentu dan dikomunikasikan dalam bahasa yang amat khas. Puisi juga mengandung nilai estetis yang bermakna, di dalam puisi terdapat ekspresi pemikiran yang membangkitkan perasaan, merangsang panca indra dalam susunan yang berirama. Puisi bisa membuat kita senang, sedih, semangat, dan marah. Puisi ditulis dan dibaca seseorang agar dapat dinikmati khalayak ramai. Sehingga puisi merupakan bentuk-bentuk tertentu dan yang ditulis dengan sedemikian indah dan menarik baik bahasa, makna, dan susunanya.

Kata puisi berasal dari bahasa yunani kuno yaitu berasal dari kata poieo atau poio yang artinya seni tertulis. Puisi menggunakan bahasa dalam kualitas estetiknya untuk tambahan selain arti semantiknya. Sastra memiliki dua fungsi, yaitu fungsi sosial dan fungsi estetika. Puisi adalah bentuk karya sastra yang mengungkapkan pikiran dan perasaan penyair yang dituangkan dalam bahasa 
atau kata-kata yang indah. Waat-Dunton Situmorang (dalam Samosir, 2013:18) menyatakan bahwa puisi adalah ekspresi yang konkret dan bersifat artistik dari pikiran manusia dalam bahasa emosional. Saat ini pengajaran dengan nilai-nilai karakter bangsa sedang diajarkan di berbagai jenjang pendidikan. Pembentukan nilai-nilai karakter bangsa juga dapat dibentuk dalam pembelajaran menulis puisi.

Halomoan dan Luthfi Maulana Nasution (2012 : 13-14) yang menjelaskan bahwa pendidikan karakter adalah usaha sadar dalam menanamkan nilai - nilai perilaku yang meliputi aspek pengetahuan, kesadaran atau kemauan, dan tindakan untuk melaksanakan nilai - nilai , baik terhadap Tuhan Yang Maha Esa, diri sendiri, sesama, lingkungan maupun kebangsaan dan semesta sehingga menjadi insan kamil. Insan kamil yang dimulai dari niat, lisan dan tindakan nyata yang berwujud adab dan perilaku baik. Pembinaan karakter juga dapat dilakukan dengan penyajian materi yang dapat direalisasikan dengan tindakan nyata dalam kehidupan sehari - hari. Pendidikan karakter akan berhasil jika dilakukan secara simultan mulai dari lingkar diri - sendiri, keluarga, masyarakat, bangsa dan semesta.

Berdasarkan pemaparan di atas, penulis tertarik untuk melakukan penelitian mengenai kemampuan menulis puisi bebas mahasiswa semester genap 2018-2019 STKIP Budidaya Binjai.

Rumusan masalah dalam penelitian ini adalah bagaimana kemampuan menulis puisi bebas mahasiswa semester genap 2017-2018 STKIP Budidaya binjai? Tujuan penelitian ini adalah untuk mengetahui kemampuan menulis puisi bebas mahasiswa semester genap 2017-2018 STKIP Budidaya binjai.

\section{Hakikat Puisi}

Puisi disebut juga ucapan atau ekspresi tidak langsung atau ucapan ke inti pati masalah, peristiwa, ataupun narasi (Pradopo, 2005: 314). Puisi bukan lagi sebuah bentuk karya sastra yang kaku dan penuh persyaratan. Puisi dalam pengertian modern adalah puisi yang bebas. Puisi merupakan aktualisasi ekspresi dan ungkapan jiwa penulisnya. Oleh sebab itu, siapa saja dapat membuat puisi, meskipun tentu tetap ada bentuk khas sebuah puisi sebagai ukuran standar yang membedakannya dengan bentuk karya sastra yang lain. Artinya setiap orang dapat 
menggunakan sarana-sarana kepuitisan seperti rima, irama, diksi, dan lainnya untuk mengintensitaskan ekspresi dan pengalaman jiwanya, bukan menjadikannya syarat pengikat. Sebagai sebuah karya sastra, puisi tetap harus memiliki kemampuan menampung segala unsur yang berkaitan dengan kesastraan. Setidaknya ada tiga aspek yang perlu diperhatikan untuk memahami hakikat puisi. Tiga aspek tersebut, yaitu: sifat seni, kepadatan, dan ekspresi tidak langsung.

\section{Unsur-Unsur Puisi}

Secara garis besar unsur-unsur puisi terbagi menjadi dua macam, yakni struktur fisik dan struktur batin (J. Waluyo,1995:206).

\section{Struktur Fisik Puisi}

\section{Diksi}

Diksi atau pilihan kata adalah kemampuan seseorang membedakan secara hendaknya disesuaikan dengan situasi dan nilai rasa yang dimiliki sekelompok masyarakat pendengar atau pembaca.

\section{Pengimajian}

Pengimajian atau daya bayang merupakan kemampuan menciptakan citra atau bayangan dalam benak pembaca. Kosasih (2003:207) mengatakan bahwa pengimajian didefenisikan sebagai kata atau susunan kata yang dapat mengungkapkan pengalaman imajinasi.

\section{Kata Konkret}

Kata konkret adalah kata-kata yang digunakan oleh penyair untuk menggambarkan suatu lukisan keadaan atau suasana batin dengan maksud untuk membangkitkan imaji pembaca, agar pembaca dapat merasakan apa yang sedang dilukiskan pengarangnya melalui kata-kata.

\section{Bahasa Figuratif (Majas)}

Dalam penulisan puisi diperlukan bahasa figuratif atau majas. Kosasih (2004:208) mengatakan bahwa majas ialah bahasa yang digunakan penyair untuk mengatakan sesuatu dengan cara pengiasan, yakni secara tidak langsung mengungkapkan makna. Majas terdiri dari beberapa jenis yaitu :

1. Majas Perbandingan

2. Majas Pertentangan 
3. Majas Pertautan

4. Majas Penegasan / Perulangan

Rima

Rima merupakan pengulangan bunyi pada puisi. Kosasih (2003:207) mengatakan bahwa "rima adalah pengulangan bunyi dalam puisi". Rima berfungsi untuk membentuk musikalitas atau orkestrasi.

\section{Tata Wajah (Tipografi)}

Tata wajah sering juga disebut sebagai susunan baris puisi atau ukiran bentuk. Tipografi adalah tatanan larik, bait, dan kalimat untuk menghasilkan suatu bentuk fisik yang mampu mendukung isi, rasa, dan suasana. Dalam puisi-puisi kontemporer, tipografi itu dipandang begitu penting sehingga menggeser kedudukan makna kata-kata.

\section{Struktur Batin Puisi}

Ada empat struktur batin puisi menurut Kosasih (2003:210) yaitu: tema, perasaan, nada, dan amanat. Struktur batin puisi tersebut akan diuraikan sebagai berikut :

a. Tema

b. Perasaan

c. Nada

d. Amanat

\section{Pencitraan}

Pencitraan adalah satu sarana kepuitisan yang digunakan oleh penyair untuk memperkuat gambaran pikiran dan perasaan pembaca.

\section{Jenis-jenis Pencitraan}
a. Citraan penglihatan
b. Citraan Pendengaran
c. Citraan Gerak
d. Citraan Penciuman
e. Citraan Pengecapan 


\section{Pendekatan dalam Telaah Sastra}

Model ini memiliki pendekatan kritis utama terhadap karya sastra yaitu :

a. Pendekatan yang menitik beratkan pada karya itu sendiri. Pendekatan ini disebut dengan pendekatan objektif

b. Pendekatan yang menitik beratkan pada penulis. Pendekatan ini disebut pendekatan ekspresif

c. Pendekatan yang menitik beratkan pada pembaca. Pendekata ini disebut pendekatan pragmatik

d. Pendekatan yang menitik beratkan pada semesta. Pendekatan ini disebut pendekatan mimetik

\section{Nilai - nilai Karakter Bangsa Indonesia}

Saat ini terdapat indikasi kuat yang mengungkapkan bahwa telah memudarnya nilai - nilai luhur yang melekat pada bangsa kita. Nilai - nilai kejujuran, kesantunan, kebersamaan mulai terkikis dengan merebaknya nilai nilai dan perilaku yang berorientasi pada pemerolehan kekayaan tanpa perlu kerja keras, kesenangan tanpa hati nurani, bisnis tanpa moralitas, politik tanpa prinsip dan semua perilaku itu cukup memprihatinkan.

Konsep penanaman nilai - nilai karakter bangsa melalui pendidikan ini terus dikembangkan oleh Mendiknas. Pada dasarnya pengembangan karakter melalui pendidikan ini bertujuan untuk mendorong lahirnya generasi yang baik (insan kamil). Hal ini ditegaskan Halomoan dan Luthfi Maulana Nasution (2012 : 13-14) yang menjelaskan bahwa pendidikan karakter adalah usaha sadar dalam menanamkan nilai - nilai perilaku yang meliputi aspek pengetahuan, kesadaran atau kemauan, dan tindakan untuk melaksanakan nilai - nilai , baik terhadap Tuhan Yang Maha Esa, diri sendiri, sesama, lingkungan maupun kebangsaan dan semesta sehingga menjadi insan kamil. Insan kamil yang dimulai dari niat, lisan dan tindakan nyata yang berwujud adab dan perilaku baik. Keberhasilan pembentukan insan kamil ini akan ditentukan oleh kerjasama berbagai pihak.

Pengembangan karakter dalam pendidikan akan mendorong peserta didik tumbuh dengan kapasitas dan komitmennya untuk melakukan berbagai hal terbaik dan melakukan segala hal dengan benar serta memiliki tujuan hidup. Halomoan 


\section{Jurnal Serunai Bahasa Indonesia \\ Vol.16, No.1, Februari 2019 \\ e-ISSN 2621-5616}

dan Luthfi Maulana Nasution (2012 : 15 ) menjelaskan bahwa tujuan pendidikan karakter dalam dunia pendidikan kita adalah :

1. Mengembangkan potensi kalbu / nurani / afektif peserta didik sebagai manusia dan warga negara yang memiliki nilai - nilai budaya dan karakter bangsa melalui aspek pedagogis.

2. Mengembangkan kebiasaan dan perilaku terpuji sejalan dengan nilai - nilai universal dan tradisi budaya bangsa yang religious.

3. Menanamkan jiwa kepemimpinan dan tanggung jawab peserta didik sebagai generasi penerus bangsa.

4. Mengembangkan kemampuan peserta didik menjadi manusia yang mandiri, kreatif, berwawasan kebangsaan , dan

5. Mengembangkan lingkungan sekolah sebagai lingkungan belajar yang aman, jujur, penuh kreativitas dan persahabatan, serta dengan rasa kebangsaan yang tinggi dan penuh kekuatan (dignity).

Sumber pengembangan nilai - nilai pendidikan karakter bangsa adalah agama, pancasila, budaya dan tujuan pendidikan nasional. Masyarakat Indonesia adalah masyarakat beragama sehingga kehidupan individu, masyarakat dan bangsa selalu didasarkan pada ajaran agama. Sedangkan Pancasila merupakan dasar negara Indonesia. Nilai - nilai budaya dijadikan dasar untuk pemberian makna terhadap suatu konsep dan arti dalam interaksi dan komunikasi antaranggota masyarakat. Selanjutnya, tujuan pendidikan nasional memuat nilai nilai kemanusiaan yang harus dimiliki bangsa Indonesia. Keempat sumber nilai inilah yang dijadikan dasar untuk merumuskan nilai - nilai karakter bangsa Indonesia yang selanjutnya akan diimplementasikan dalam dunia pendidikan di Indonesia.

Halomoan dan Luthfi Maulana Nasution (2012 : 20 - 22 ) memaparkan bahwa sumber pengembangan nilai - nilai pendidikan karakter bangsa adalah agama, pancasila, budaya dan tupenas (tujuan pendidikan nasional). Berdasarkan keempat sumber nilai itu, Balitbang Puskur Kemdiknas mengidentifikasi 18 butir nilai untuk pendidikan budaya dan karakter bangsa, yaitu : 1) religius, 2) jujur, 3) toleransi, 4) disiplin, 5) kerja keras, 6) kreatif, 7) mandiri, 8) demokratis, 9) rasa 
ingin tahu, 10) semangat kebangsaan, 11) cinta tanah air, 12) menghargai prestasi,bersahabat/komunikatif, 14) cinta damai, 15) gemar membaca, 16) peduli lingkungan, 17) peduli sosial dan 18) tanggung jawab.

\section{METODE}

Penelitian ini menggunakan penelitian deskriptif kualitatif, di mana subjek penelitian berjumlah 51 orang. Penelitian ini dilaksanakan di semester genap 2017-2018. Data dalam penelitian ini diperoleh melalui observasi atau pengamatan langsung. Untuk menganalisis data yang diperoleh penulis menggunakan langkah-langkah sebagai berikut:

1). Menghitung hasil kemampuan siswa dalam menulis puisi

2). Menetapkan kemampuan siswa dalam menulis puisi yang berdasarkan klasifikasi nilai:

$\begin{array}{ll}\text { Nilai } & \text { Kualitas } \\ 80-100 & \text { Baik Sekali } \\ 66-78 & \text { Baik } \\ 56-65 & \text { Cukup } \\ 40-45 & \text { Kurang } \\ 0-39 & \text { Buruk }\end{array}$

3). Menghitung mean atau nilai rata-rata mahasiswa

$\mathrm{M}=$ Jumlah nilai keseluruhan Jumlah siswa

4). Membuat persentase kemampuan menulis puisi bebas oleh mahasiswa

$$
\begin{aligned}
& \text { PI }=\underline{\mathrm{FI}} \\
& \text { Keterangan: } \\
& \text { PI : Proporsi dari kategori tertentu } \\
& \text { FI : Frekuensi mutlak dari sampel } \\
& \mathrm{N} \text { : Jumlah Sampel }
\end{aligned}
$$




\section{HASIL DAN PEMBAHASAN PENELITIAN}

Tes ini diberikan kepada mahasiswa semester genap 2017-2018 STKIP Budidaya Binjai dengan lama waktu 60 menit. Pengelolaan data yang merupakan data mentah mahasiswa dalam kemampuan menulis puisi bebas dengan tema nilai-nilai karakter bangsa. Berikut ini langkah-langkah dalam mencari hasil data penelitian.

1. Menghitung skor siswa, hal tes essai yang dilakukan oleh siswa dihitung berdasarkan jawaban yang benar.

2. Mengubah skor menjadi nilai akhir

3. Mengubah nilai yang didapat oleh mahasiswa dari tes essai yang diberikan kemampuan menulis puisi mahasiswa semester genap 2017-2018 STKIP Budidaya Binjai dapat menggunakan skor yang bersstandart $100 \%$

4. Mengubah skor mentah mahasiswa dari tes essai hasil kemampuan menulis puisi mahasiswa semester genap 2017-2018 STKIP Budidaya Binjai.

\begin{tabular}{|l|l|l|}
\hline No & \multicolumn{1}{|c|}{ Aspek yang Dinilai } & \multicolumn{1}{c|}{ Presentase } \\
\hline 1 & Tema & $650 / 1980 \times 100 \%=32,3 \%$ \\
\hline 2 & Diksi & $405 / 1980 \times 100 \%=20,4 \%$ \\
\hline 3 & Gaya bahasa & $435 / 1980 \times 100 \%=21,9 \%$ \\
\hline 4 & Kesesuaian isi & $557 / 100 \% \times 100 \%=28,1 \%$ \\
\hline
\end{tabular}

Adapun persentase pada peringkat nilai yang didapat oleh masing-masing mahasiswa dapat diliha pada tabel di bawah ini:

\begin{tabular}{|c|c|c|c|}
\hline Angka & Huruf & Jumlah Mahasiswa & Persentase \\
\hline $80-100$ & Sangat Baik & 15 & $15 / 51 \times 100 \%=29,4 \%$ \\
\hline $66-79$ & Baik & 30 & $30 / 51 \times 100 \%=58,8 \%$ \\
\hline $56-65$ & Cukup & 6 & $6 / 51 \times 100 \%=11.8 \%$ \\
\hline $40-55$ & Kurang & - & - \\
\hline $0-39$ & Buruk & - & - \\
\hline & Jumlah & 51 & $100 \%$ \\
\hline
\end{tabular}

Berdasarkan uraian di atas dapat diketahui bahwa kemampuan menulis puisi mahasiswa semester genap 2017-2018 STKIP Budidaya Binjai sudah baik. 


\section{SIMPULAN}

Berdasarkan hasil analisis data dan pembahasan dalam penelitian ini yang telah dijabarkan pada bab sebelumnya, maka peneliti mengambil kesimpulan bahwasannya hasil analisis data dan pembahasan terhadap hasil penelitian menunjukkan bahwa nilai rata-rata siswa sebesar 75. Adapun hasil data yang diperoleh dari mahasiswa yang berjumlah 51 orang dalam tes menulis puisi dinyatakan 15 mahasiswa atau 29,4 \% memperoleh nilai sangat baik (80-100), 30 mahasiswa atau 58,8 \% memperoleh nilai baik (66-79), 6 orang atau 11,8\% memperoleh cukup (56-65). Dan tidak ada yang mendapatkan nilai kurang bahkan buruk.

\section{REFERENSI}

Halomoan, Muhammad dan Luthfi Maulana Nasution. 2012. Mengembangkan dan Mengintegrasikan Nilai - nilai Pendidikan Karakter ke dalam Dokumen 1 dan 2 KTSP. Medan : La - Tansa Press.

Kosasih, E. 2004. Ketatabahasaan dan Kesusastraan. Bandung: Yrama Widya.

Latif, Yudi. 2009. Menyemai Karakter Bangsa. Jakarta : PT Kompas Media Nusantara.

Tansliova, Lili. 2014. "Nilai - nilai Karakter Bangsa pada Novel "Ranah 3 Warna" dan "Rantau 1 Muara" Karya Ahmad Fuadi Serta Kontribusinya Terhadap Pendidikan Karakter”. Tesis. Pendidikan Bahasa Indonesia. Universitas Muslim Nusantara. Medan.

Pradopo, Rachmat Djoko dkk. 2003. Metodologi Penelitian Sastra. Yogyakarta: Hanindita.

Moleong, Lexy J. 2010. Metodologi Penelitian Kualitatif. Bandung: Remaja Rosdakarya.

Samosir, Tiorida 2013. Apresiasi Puisi. Bandung : Yrama Widya.

Waluyo, Herman J. 1994. Pengkajian Cerita Fiksi. Jakarta: Sebelas Maret University Press. 